\title{
REFLEXIÓN SOBRE LOS IDEALES
}

Santiago Vidal Muñoz

INTRODUCCIÓN

Un problema frecuentemente olvidado es el de los ideales humanos que interesan a la temática de la Psicología, la Sociologia y de diversas disciplinas, entre ellas de orden educativo-moral. La mayor complejidad de este tema, se revela en el amplio contexto de la realidad sociohistórico-cultural, en los medios concretos de la naturaleza y del espíritu. La brevedad de este trabajo, sólo nos permite indicar que en el trasfondo del problema de los ideales, figuran los valores compartidos por grupos sociales en la personalidad psicológica y social y el dominio de la persona en cuanto tema esencial en la Filosofía del Hombre.

Existe una muy estrecha relación entre los valores, los fines de la vida humana y sus ideales.

Así un propósito muy general de este trabajo es contribuir al esclarecimiento del concepto y función de los ideales de vida, en vista de una mayor comprensión de la existencia y la vida, importando la personalidad de los jóvenes en la actualidad y su proyección al futuro. Si calificamos aquí este pensar, diremos que es una breve reflexión sobre el complejo problema de los ideales y planes de vida de la juventud.

Cada definición de 'ideal' tiene un trasfondo filosófico, moral y científico. El término 'ideal' en los análisis, puede considerarse como adjetivo y como sustantivo.

1) Como adjetivo tiene dos sentidos en el juicio de Zaragueta. El primero, es de un concepto abstracto, de orden lógico, por ejemplo, ideal en oposición a la realidad. Además, tiene un sentido metafísico, en el cual se contrapone, ontológica- 
mente, a lo real, como ser irreal, imaginario. Algo dado como "irrealizable o realizable, pero aún no realizado". Aparece aquí la secular controversia filosófica entre idealismo y realismo, con toda la complejidad del tema. En este caso también hay dos interpretaciones: a) el ideal es lo que satisface todas las exigencias del pensamiento, pero faltándole toda realidad, todavía no existente (Kant). b) El ideal es lo que, satisfaciendo todas las exigencias del pensamiento es en y por e/ pensamiento en el sentido pleno de la palabra (postkantianos). "Ninguna realización material, ninguna entrada a la existencia podría añadirle nada". Es 'perfecto'.

Al significado ontológico, se le agrega el significado axiológico, en el cual ideal se opone a lo imperfecto, significando 'lo perfecto' lo insuperable.

II) Como sustantivo, el concepto ideal, se le puede considerar: a) un "modeloo patrón de la actividad práctica u objetivo de la voluntad", pero apetecible como valioso. b) "Lo ideal es lo óptimo" en un orden cualquiera de bienes en la jerarquía de los bienes entre sí, por lo mismo no plenamente realizable. c) Por último, los ideales de vida personal o de un pueblo se conciben como "fuerzas ascensionales en la vida mental". Constituyen una suerte de "categoría del pensamiento esencialmente dinámica". Los ideales pueden involucrar lo que se aspira o anhela, espiritual o materialmente y lo que se desea impulsivamente.

Al pensar en la esencia y el concepto de 'ideal', aquí no consideramos 'ideal' en el sentido de adjetivo de los objetos ideales, de la Teoría del Conocimiento. Hay varias acepciones de este concepto, según sea la filosofía, la ciencia y otras disciplinas y experiencias que se tomen como punto de partida. La postura intelectual del investigador circunscribe el campo de la reflexión. Frecuentemente hablamos de 'ideales humanos', aún cuando basta el término 'Ideales', pues el ser humano es el único capaz y apto para tener ideales y proponerse fines inmanentes y trascendentes.

J. Ferrater Mora, subraya varios sentidos de 'ideal': modelo nunca alcanzado por una realidad; lo perfecto en su género; una exigencia moral (anhelo moral y de educación); como proyección de una idea y como exigencia de la razón pura, en Kant. "El ideal se consigue, cuando una idea ha llegado a desplegarse, aún cuando sea aproximadamente, según todas sus posibilidades" (Brügger).

El ideal puede ser representado como "una figura lejana, todavia no encarnada, dotada del carácter de fin. O se concibe el ideal existiendo en determinada esencia. En este caso la 'idea' de Platón es ideal: existe como una realidad suprasensible. La idea de BIEN es así, el 'ideal' de todos los ideales". Esta idea aparece en el cristianismo, en cuanto 'imagen de Dios'. Dios es el ideal absoluto, pues reúne todas las perfecciones puras con máxima perfección, o según el conjunto de sus posibilidades. "Dios, en Kant, aparece como 'ideal trascendental', a semejanza de la idea platónica: Dios es el arquetipo conforme al cual ha sido configurado todo lo terrestre y finito"... pues "participa de ÉL". 
Como exigencia de la razón pura el ideal nos es dado, según Kant, en el campo de la experiencia. "Los ideales tienen un uso regulativo, es decir, sirven de normas para la acción y el juicio, "encaminan a la razón". Si se insiste en la idea de 'modelo', hay que suponerlo como jamás alcanzado en una realidad. Aun cuando, desde el punto de vista de la creatividad de la persona, siempre será posible aproximarse a esos paradigmas y aun superarlos, creando nuevos ideales en la historia.

\section{DETERMINACIÓN REAL Y ESPIRITUAL DE LOS IDEALES}

El problematismo de los ideales de la juventud está inserto en el tema de los ideales humanos, pues el hombre es el único viviente que se propone ideales y fines. El ser y el deber ser del hombre se concibe, así, entre realidad en situación concreta, e ideales posibles o imposibles en el futuro.

Se puede hablar de condiciones en la vida humana que existen para que surjan ideales, se deplieguen en su futuro en el cual son posibles nuevos ideales; otros desaparecen. Es indudable que los ideales son motivados y determinados en la vida humana sobre todo juvenil, según diversos factores e instancias. Anotemos algunos.

1) Los ideales se configuran y vis/umbran de distinta manera, particularmente en las diversas etapas y edades de la vida, en el desarrollo mismo de la personalidad y de la conciencia moral del niño, del adolescente, de la juventud y en los años de adultez.

2) Los ideales aparecen y se transmiten, según los modos de sery de hacer de los pueblos y sus comunidades, conforme a sus tradiciones, costumbres, instituciones...

3) Según las épocas o períodos histórico-culturales y el correspondiente desarrollo de las sociedades.

4) Según el estado y evolución de los sistemas y estadios cultural-educativos.

En general, hay múltiples motivaciones que posibilitan la vivencia y experiencia de los ideales, en verdad son motivaciones reales y naturales y deteminaciones motivacionales, espirituales, propias del hombre, En última instancia, como ocurre con frecuencia, los ideales presuponen alguna concepción del mundo, explícita o implícita, una concepción de la vida, la cultura, culminando, en parte, en una teoría del hombre y de la educación como ser natural y personal. En un terreno metafísico, que no es dable explicitar aquí, el hombre, su vida, sus ideales y todo lo que le concierne, presuponen cuestiones del ser y del valor, del ser y el deber ser con su impronta ética, tan valiosa para la educación. Ideales de cualquier orden, suponen asi una adhesión a determinados valores o valores predominantes en una sociedad dada, sobre todo, de orden religioso, ético y estético; de orden lógico, utilitario y 
vital, si seguimos en esto a Max Scheler. Sería necesario estudiar la relación entre valor y fines humanos e ideales, de la juventud primordialmente.

Para comprender la historia, la actualidad y las posibilidades del futuro-telón de fondo de los ideales-, será preciso tener ciertos principios y valores y no exc/usivamente relativos. La "felicidad" buscada, en la línea de Aristóteles, nos parece que sería un ideal humano perenne, siempre que se tome en su doble dimensión de ideal relacionado con cosas materiales y con la vida espiritual.

Los ideales son motivaciones espirituales y no exclusivamente naturales. Intervienen en la motivación y causación de la acción humana, como asimismo crecen al ritmo de los pueblos y sus culturas, dando sentido a la existencia, aun cuando con frecuencia son meras utopías o sueños. Crecen, decrecen hasta desvanecerse o bien se infiltran unos a otros en diversos ámbitos de la vida, en el ámbito de la persona humana y de orden psicosomático y psicosocial en el acontecer históricocultural. Los ideales de la juventud, o como integrantes dinámicos de la personalidad son ineludibles para la comprensión de una sociedad de individuos personales y no de cosas o robot. Los ideales se crean y recrean en todo hombre libre o esclavo.

La determinación real y espiritual de los ideales, en general está relacionada íntimamente con su diversidad y sus cambios. Esta aserción conduce a una postura relativista en su valoración histórica. De ahí la importancia que poseen algunos principios y valores que serían absolutos y objetivos a través del acontecer humano. No obstante, la determinación de los ideales, es necesario reafirmarla para comprender la funcionalidad y el valor que tienen los fines e ideales educativos en la existencia real y concreta.

La calidad y variaciones de los ideales en el tiempo puede comprenderse considerando diversos puntos de vista. Por ejemplo, el nivel de desarrollo de sociedades diferentes; a veces se aprecian diversos ideales -aun opuestos- en los mismos estratos sociales.

Hay que considerar el sexo. Los ideales varían, particularmente, si consideramos esta cuestión, desde el punto de vista de la Psicología y la Sociología. Hay ideales según el tipo de grupos étnicos, religiosos, etc. Es evidente la influencia que tienen en la determinación y cambios de los ideales las costumbres, las tradiciones, los intereses y aspiraciones de las comunidades y pueblos.

Se puede también enfocar los ideales desde el punto de vista de su perdurabilidad desde tempranos años en la vida, en general, hasta la muerte. Hay ideales transitorios en la vida personal y en la sociedad y otros que perduran en ciertos períodos y ante lo imprevisto y las contingencias en la vida individual y social.

Con frecuencia, la no existencia o la limitación del surgimiento de ideales es propia de los neuróticos, de los inadaptados por causas patológicas, como asimismo de individuos de vida primitiva o vitalmente disminuidos.

Tanto más amplio es el espectro de ideales de una sociedad, cuanto mayor sea 
la probabilidad de que se logre una sana adaptación psicosocial al ambiente total y concreto. Además, hay que considerar en el estudio de los ideales en función de su intensidad y fuerza en el seno de las comunidades locales, nacionales o internacionales. Los grandes ideales y fines de las Naciones Unidas, pertenecerían al último caso.

Es decisiva la perspectiva que se tome para aprehender, comprender y valorar los ideales. Pueden referirse a una persona o a una sociedad en determinadas zonas del planeta. Hoy existen perspectivas planetarias y cósmicas. Según Linton, la pareja valórica de agrado-desagrado juega un papel importante en la selección de ideales y en la adhesión a ellos, frente a las expectativas y aspiraciones de un individuo, sobre todo si es joven... La adolescencia y la juventud son períodos de descubrimiento de ideales y configuración de planes de vida.

Se presentan en la vida personal ideales y fines culturales, sociales, religiosos, ideológicos, educativos, profesionales, etc.

Probablemente, con mayor edad y madurez intelectual y moral, sean mejor visualizados ideales de gran valor, para la vida social, nacional o internacional. Además del valor vital, polarmente dado, de agrado-desagrado, tienen destacada gravitación ideales culturales y de la conducta individual. Los valores éticos, están relacionados con el ideal de vida en vista del futuro (el ser bueno y el ser malo, el ser justo, el ser injusto, el ser responsable, el ser irresponsable). La teoría de los ideales tiene estrecha relación con la teoria de los valores y, con ello, en la vida humana total, tanto en la existencia individual como en la colectiva y la humanidad toda. Así se pueden entender en la historia, los ideales en la convivencia libre y pacífica de personas y naciones.

Desde un punto de vista histórico, hay varios sentidos del concepto de ideal. Si aceptamos que la utopia tiene un parentesco conceptual con los ideales, la misma "República" de Platón implicaría un ideal de vida, de sociedad y de cultura. Los ideales del hombre se manifiestan a través de los siglos. Así, figuran los ideales de los espartanos y de los atenienses. Es el caso del cristianismo, ideal del hombre cristiano, preponderantemente en el medioevo y en éste el ideal de los caballeros. También habrá ideales del hombre liberal, del hombre democrático, del marxista, del existencialista, etc.

Ideal sería un concepto principalmente emotivo-intelectual que abarca aspectos de la propia interioridad, como factores propiamente subjetivos, dados en los fenómenos psicológicos. No obstante, existen manifestaciones objetivas, derivadas de las observaciones de la conducta individual y social. Los ideales tienen influencia en la propia vida personal y de la sociedad, con todas las complicaciones que supone la afirmación de los ideales, aun cuando de ellos se afirme, con frecuencia, su simple posibilidad o su irrealidad, mirando desde aquí y ahora con un movimiento a la trascendencia. 
En la vida humana, esos ideales se relacionan con las vocaciones, los intereses, las aspiraciones, etc. Todas esas instancias tienen el signo de la futuridad. Los ideales aparecieron en el pasado, son de hoy para el futuro. Examinados con óptica histórica, los ideales surgen en generaciones jóvenes y adultos coetáneos, influyendo unos sobre otros, realizándose total o parcialmente o, simplemente. quedando sin realización.

Los fines y los ideales otorgan, en general, un sentido a la existencia y la vida. Una juventud sin ideales, parece una juventud vacía en su destino, más aún en nuestros tiempos, pues hay una multiplicidad y variedad de obstáculos que enfrentan las sociedades contemporáneas para convivir y sobrevivir sobre todo sus juventudes sin ideales a la vista. La adolescencia y la juventud aparecen íntimamente relacionadas con el problema, destacado desde hace años, de la falta de ideales y de planes de vida. El tema interesa particularmente a la psicología, la sociología, la antropología cultural y social, a la moral y la educación, al estudio de la salud, del trabajo, de la recreación, etc. De ahi, en parte, la importancia de lograr un conocimiento interdisciplinario en la concepción del "hombre entero", integro... Cabría acaso pensar que la historia podría ser considerada una sucesión de exitos y fracasos de las personas individuales en sociedad. Ideales logrados, en parte siquiera, son una apertura al progreso espiritual y material. Los ideales esfumados y no cumplidos, son signo de frustración y pesimismo.

\section{IDEALES EN LA EDUCACION}

Interesantes son los estudios sobre ideales en la edad escolar, tanto en la vida intraescolar como extraescolar. Los planes de vida se han definido como "serie de actividades simplemente imaginadas que el sujeto se propone ejecutar con el propósito de modificar su personalidad, acercándolo al ideal que de sí mismo se ha forjado".

Francisco Larroyo, en su libro "Sistema de la Filosofía y la Educación", trata el tema de Realidad e ldeal, ser y deber ser en la Educación. Señala que la antinomia educativa tiene que ver con el SER (su realidad) y el DEBER SER de la educacion (su ideal). Refiriéndose al pensar metafísico, dice: "Los hechos son; no cabe preguntarse lo que deben ser. Si el ideal es algo que no es, sino que debe ser, SER Y DEZER SER son términos irreductibles".

En verdad, agrega Larroyo, no existe una separación insuperable entre realidad e ideal. En la vida educativa, la diferencia entre uno y otro es sólo una "diferencia de niveles". Aprender algo es finalidad ideal. Con esfuerzo, "logra cambiar su realidad educativa": EL IDEAL SE HACE REAL. Conquistando hoy un ideal convertido en realidad en el futuro será sin dudas, superado por otros ideales. Los ideales, a través del proceso educativo, se convierten en un importante elemento 
para las indecisiones educativo-morales, insertas en los planes de vida de las generaciones jóvenes.

Al finalizar, diremos que una reflexión sobre los ideales tiene relación, directa o indirectamente, con una concepción del "hombre entero", la cual logra su pleno sentido a través de un conocimiento integrado y no desintegrado o atomizado.

Los ideales comprenden un complejo de realidades psicosociales, socioeducativas y culturales en la historia espiritual del hombre. Válido esto, particularmente para el conocimiento y comprensión de la juventud en el mundo contemporáneo.

Los ideales se muestran en intima conexión con los valores y fines, sean éstos inmanentes o trascendentes a la vida humana.

Los ideales desde el punto de vista psico-socio-cultural e histórico, constituyen una relación de sentido que exige intersubjetivamente compartirlos en una sociedad de individuos personales.

$\mathrm{El}$ estudio de los ideales exige un desarrollo, en profundidad y extensión, en una perspectiva interdisciplinaria: es parte relevante de la realidad y problemas del hombre real y del destino de sus nuevas generaciones. 